\title{
Intrathoracic esophageal replacement by in situ tissue-engineered esophagus
}

\author{
Yuen Nakase, MD, PhD, a,e Tatsuo Nakamura, MD, PhD, ${ }^{\text {b }}$ Shuichi Kin, MD, PhD, ${ }^{a}$ Susumu Nakashima, MD, PhD, ${ }^{a}$ \\ Tetsuji Yoshikawa, MD, PhD, ${ }^{a}$ Yoshiaki Kuriu, MD, PhD, ${ }^{a}$ Chohei Sakakura, MD, PhD, ${ }^{a}$ Hisakazu Yamagishi, MD, PhD, \\ Junji Hamuro, PhD, ${ }^{\mathrm{c}}$ Yoshito Ikada, $\mathrm{PhD},{ }^{\mathrm{d}}$ Eigo Otsuji, $\mathrm{MD}, \mathrm{PhD}{ }^{\mathrm{a}}$ and Akeo Hagiwara, MD, $\mathrm{PhD}^{\mathrm{e}}$
}

From the Department of Surgery and Regenerative Medicine, Division of Surgery and Physiology of Digestive System, Graduate School of Medical Sciences, Kyoto Prefectural University of Medicine $e^{a}$; the Department of Bioartificial Organs, Institute for Frontier Medical Science, Kyoto University; the Department of Ophthalmology, Kyoto Prefectural University of Medicine, ${ }^{\mathrm{c}}$ Kyoto, Japan; the Department of Bioenvironmental Medicine, Nara Medical University, Nara, $\mathrm{Japan}^{\mathrm{d}}$; and the Department of Medical Life Systems, Doshisha University, Kyoto, Japan. ${ }^{\mathrm{e}}$

This work was supported in part by a grant for the Third-Term Comprehensive 10Year Strategy of Cancer Control from the Ministry of Health, Labor and Welfare of Japan.

Received for publication Nov 2, 2007; revisions received Feb 26, 2008; accepted for publication May 4, 2008.

Address for reprints: Yuen Nakase, MD, $\mathrm{PhD}$, Department of Surgery and Regenerative Medicine, Division of Surgery and Physiology of Digestive System, Graduate School of Medical Science, Kyoto Prefectural University of Medicine, Kawaramachi-Hirokoji Kajiicho 465, Kamigyo-ku, Kyoto 602-8566, Japan (E-mail: yuen-n@ koto.kpu-m.ac.jp).

J Thorac Cardiovasc Surg 2008;136:850-9

$0022-5223 / \$ 34.00$

Copyright $(2008$ by The American Association for Thoracic Surgery

doi:10.1016/j.jtcvs.2008.05.027
Objective: This study aimed to evaluate in situ tissue-engineered esophagus in a canine model after experimental resection and replacement of a full circumferential defect of the intrathoracic esophagus.

Methods: Two types of scaffolding were fabricated. In the $\mathrm{KF}(+)$ group $(\mathrm{n}=6)$, oral keratinocytes and fibroblasts cultured on human amniotic membrane were sheeted on polyglycolic acid felt with smooth muscle tissue and were then rolled around tubes. In the $\mathrm{KF}(-)$ group $(\mathrm{n}=6)$, the same procedure was followed, but the keratinocytes and fibroblasts were omitted. Both scaffolds were wrapped in omentum and implanted in the abdomen. In the $\mathrm{KF}(+)$ group, at 3 weeks after implantation, the scaffold developed into a tube with a well-differentiated lumen of stratified squamous cells surrounded by a thick smooth muscle-like tissue (in situ tissue-engineered esophagus). A part of the esophagus was resected and replaced by the graft in the same dogs.

Results: In the $\mathrm{KF}(-)$ group, strictures developed after esophageal replacement, with almost complete obstruction within 2 to 3 weeks. In contrast, in the $\mathrm{KF}(+)$ group, the in situ tissue-engineered esophagus showed good distensibility and the dogs remained without feeding problems through 420 days. Esophageal peristalsis transferred food to the stomach, despite the absence of peristaltic activity in the in situ tissue-engineered esophagus itself. The thickness of the squamous epithelial layer and the smooth muscle layer of the in situ tissue-engineered esophagus were similar to that of the adjacent native esophagus.

Conclusion: The in situ tissue-engineered esophagus can successfully replace the intrathoracic esophagus, and this procedure may offer a promising surgical approach to esophageal diseases.

$\mathrm{T}$ The current surgical approach to esophageal diseases such as long-gap esophageal atresia and malignant or severe benign disease involves replacement with the colon, stomach, or small intestine. ${ }^{1}$ We thought that esophageal regeneration was preferable to esophageal reconstruction with other digestive tract tissues because it avoids loss of the normal functions of digestion and absorption. Furthermore, in some cases, reconstruction by stomach or intestine cannot be performed because of previous abdominal operations. Esophageal regeneration will be useful for such patients who are lacking another suitable substitute.

We pursued organ tissue engineering with autologous cells to avoid transplantation problems such as rejection, long-term immunosuppression, donor scarcity, ethical issues, and infection. In our previous studies, $\mathrm{we}^{2,3}$ obtained promising results by seeding autologous smooth muscle cells on the collagen scaffold for regeneration of the small intestine in a canine model. The smooth muscle layer regenerated, but the graft shrank. We considered the absence of an epithelial cell layer to be one explanation of these results. Ohki and associates ${ }^{4}$ reported that implantation of tissue-engineered autologous oral mucosal epithelial cell sheets onto esophageal ulcerations prevented scar formation and shrinkage. In 


\section{Abbreviations and Acronyms}

$\alpha$-SMA $=\alpha$-smooth muscle actin

ITEE = in situ tissue-engineered esophagus

PBS = phosphate-buffered saline

PGA $=$ polyglycolic acid this study we used cultured autologous squamous cells on human amniotic membrane with polyglycolic acid (PGA) nonwoven fabric felt and autologous smooth muscle tissue as scaffolds for autologous in situ tissue-engineered esophagus (ITEE) in a canine model. We evaluated them after experimental resection and replacement of a full circumferential defect of intrathoracic esophagus.

\section{Material and Methods}

\section{Overview of Experimental Design}

Twelve female beagle dogs less than 2 years of age and weighing 9 to $11 \mathrm{~kg}$ were divided into two groups. In the $\mathrm{KF}(-)$ group, the scaffolds were implanted into the abdominal cavity and esophageal replacements were done after 3 weeks. In the $\mathrm{KF}(+)$ group, at first, the oral mucosal layer and blood serum were collected and the cells cultured on a human amniotic membrane. After 1 week, epithelial sheets were prepared, the scaffolds with epithelial sheets were implanted into the abdominal cavity, and esophageal replacements were done after 3 weeks. The animal care, housing, and surgery followed the Rules and Regulations of the Committee for Animal Research of the Kyoto Prefectural University of Medicine, Japan.

\section{Human Amniotic Membrane}

Human amniotic membrane, which has been used clinically for ocular surface regeneration, was provided from ArBlast Co, Ltd (Kobe, Japan). ${ }^{5-7}$ The amniotic membrane was obtained during elective cesarean section procedures. The preparation of amniotic membrane has been previously reported. ${ }^{5-7}$ In brief, under sterile conditions, the membranes were washed with phosphate-buffered saline (PBS) (Invitrogen, Carlsbad, Calif) that contained an antibiotic ( $5 \mathrm{~mL} 0.5 \%$ levofloxacin). The amniotic membrane was stored at $-80^{\circ} \mathrm{C}$ in a modified medium (Dulbecco's modified Eagle's medium; Gibco BRL, Rockville, Md) and glycerol (Wako Pure Chemical Industries, Osaka, Japan) in a ratio of 1:1 by volume. Immediately before use, the amniotic membrane was thawed, washed 3 times with sterile PBS containing the antibiotic, and cut into approximately $10 \times 10-\mathrm{cm}$ pieces. The overlying amniotic epithelial cells were removed by incubation with $0.02 \%$ ethylenediamine tetraacetic acid (Nacalai Tesque Co, Kyoto, Japan) at $37^{\circ} \mathrm{C}$ for 2 hours, followed by gentle scraping with a cell scraper (Nunc International, Naperville, Ill).

\section{PGA Nonwoven Fabric Felt}

We used PGA nonwoven fabric felt (Neoveil; Gunze, Co, Ltd., Kyoto, Japan), which has been used clinically in abdominal and pulmonary operations to seal bile and air leakage, respectively. ${ }^{8-10}$ Neoveil felt is a soft, thin $(0.15-\mathrm{mm}$ thick) absorbable sheet that can closely fit to irregular surfaces.

\section{Isolation and Culture of Oral Keratinocytes and Fibroblasts}

We modified previous culture methods ${ }^{5-7}$ by using autologous fibroblasts instead of mouse 3T3 feeder cells. The dogs were premedicated by intramuscular administration of atropine sulfate $(0.05 \mathrm{mg} / \mathrm{kg})$. They were then anesthetized with ketamine hydrochloride $(15 \mathrm{mg} / \mathrm{kg})$ and xylazine hydrochloride $(3 \mathrm{mg} / \mathrm{kg}$ ) and intubated endotracheally. During the procedure, halothane and nitrous oxide gas were used under mechanical ventilation to maintain anesthesia. Oral mucosal tissues were obtained from anesthetized dogs. In addition, $30 \mathrm{~mL}$ autologous blood serum was extracted from venous whole blood samples. Oral mucosal samples were cut into small explants and washed 3 times in PBS solution containing penicillin-streptomycin $(50 \mathrm{IU} / \mathrm{mL})$ and amphotericin $\mathrm{B}(2.5 \mu \mathrm{g} / \mathrm{mL})$ (Invitrogen) for 10 minutes at room temperature. The explants were incubated with $1.2 \mathrm{IU}$ dispase at $37^{\circ} \mathrm{C}$ for 1 hour. Epithelial sheets were separated from the full-thickness oral mucosal samples with forceps, pooled in 60 -mm culture dishes containing $5 \mathrm{~mL} 0.25 \%$ trypsin ethylenediamine tetraacetic acid, and incubated at $37^{\circ} \mathrm{C}$ for 5 minutes with gentle pipetting to aid tissue dissociation. Trypsin activity was terminated by washing the culture medium composed of Dulbecco's modified Eagle's medium (Invitrogen) and defined keratinocyte serum-free medium (Invitrogen) (1:1 mixture) with penicillin-streptomycin (50 $\mathrm{IU} / \mathrm{mL})$ and amphotericin B $(2.5 \mu \mathrm{g} / \mathrm{mL})$ and $10 \%$ autologous blood serum. The cell suspension was filtered through a nylon cell strainer and centrifuged twice at $1000 \mathrm{rpm}$ for 5 minutes. The resultant cell pellet was resuspended in the culture medium at a density of $1 \times 106$ cells/mL (keratinocyte suspension). After the removal of epithelial sheets, the oral mucosal samples were minced with scissors, incubated with $0.1 \%$ collagenase I at $37^{\circ} \mathrm{C}$ for 2 hours, and passed through a nylon cell strainer. The cell suspension was centrifuged at $1000 \mathrm{rpm}$ for 5 minutes, and the resultant cell pellet was washed twice with PBS solution and resuspended in the culture medium at a density of $1 \times 105$ cells $/ \mathrm{mL}$ (fibroblast suspension). The keratinocyte and fibroblast suspensions were mixed and seeded onto denuded amniotic membrane spread, epithelial basement membrane side up, on the bottom of a Transwell culture insert (100-mm dish with $75-\mathrm{mm}$ Transwell Insert; Corning, New York, NY). The cultures were incubated at $37^{\circ} \mathrm{C}$ under a humidified atmosphere of $5 \% \mathrm{CO}_{2}$ in air. The culture medium was replaced every 2 to 3 days. 


\section{Scaffold Preparation and Abdominal Implantation}

After the dogs were anesthetized, a midline incision was made on the abdomen. The smooth muscle tissue was resected from the anterior wall of the stomach $(1 \times 1 \mathrm{~cm})$ and 3-0 silk sutures were used to close the defect in the smooth muscle layer. The resected smooth muscle tissue was washed with PBS and then minced with scissors to grainy paste and sheeted on PGA felt (PGA felt with smooth muscle tissue). Two types of scaffolds were fabricated: in the $\mathrm{KF}(-)$ group ( $\mathrm{n}=6$ : A-1 to A-6), human amniotic membrane alone was sheeted on PGA felt with smooth muscle tissue (Figure 1, $A$ ); and in the $\mathrm{KF}(+)$ group $(\mathrm{n}=6$ : B-1 to B-6), autologous oral keratinocytes and fibroblasts on human amniotic membrane were sheeted on PGA felt with smooth muscle tissue (Figure 1, $B$ ). The scaffolds were rolled around a polypropylene tube that was $3 \mathrm{~cm}$ in length and $2 \mathrm{~cm}$ in diameter and wrapped with the omentum using 3-0 Vicryl sutures (Ethicon, Inc, Somerville, NJ) (Figures $1, C$ and $D$ ). The abdominal incision was closed in 2 layers with 1-0 silk sutures.

\section{Esophageal Replacement Procedure}

Esophageal replacement was performed 3 weeks after the abdominal implantation. The scaffolds developed into soft tubular tissue (Figure 1, $A$ and $B$ ). They were elevated into the right thoracic space through the right hemidiaphragm as a pedicle graft. Before replacement, biopsy specimens of the scaffolds were obtained for microscopic analysis. Gastrostomy was performed and the abdominal incision was closed. A right thoracotomy was subsequently performed through the fifth intercostal space, and the thoracic esophagus was mobilized $5 \mathrm{~cm}$ from diaphragm. A 3 -cm length of the esophagus was resected and replaced by the graft. The anastomosis was completed with 3-0 Vicryl sutures (Ethicon) (Figure 1, $C)$. Metal clips were placed at the cut ends of the native esophagus as markers (Figure 1,D). The chest incision was closed in 2 layers with 1-0 silk.

\section{Postoperative Procedure}

The dogs were allowed free access to water and were fed calf milk replacer (Snow Bland Seed, Sapporo, Japan), 80 calories/kg per day, through the gastrostomy for 7 days. Subsequently, oral feeding was reintroduced with calf milk replacer and solid diet (Oriental Yeast, Tokyo, Japan). An antibiotic (cefazolin sodium $50 \mathrm{mg} / \mathrm{kg}$ per day, intramuscularly) was administered for 5 days. The contrast medium, an amidotrizoic acid (Gastrografin; Schering, Osaka, Japan) mixed with milk, was given once a week after the esophageal reconstruction. While the dogs drank this contrast medium, esophagography was performed. The side views of esophagography of the intrathoracic esophagus were taken and peristalsis and food passage were evaluated. One dog was humanely killed at each of the following times: 10, 20, 50, and 70 weeks after the replacement operation, or when they were no longer able to eat. The differences in outcome between the $\mathrm{KF}(-)$ group and the $\mathrm{KF}(+)$ group were measured by the $\chi^{2}$ test.

\section{Histologic, Immunohistochemical, and Immunofluorescence Analyses}

Tissues were fixed with $10 \%$ buffered formalin, processed for embedding in paraffin, sectioned at $4-\mu \mathrm{m}$ thickness, and
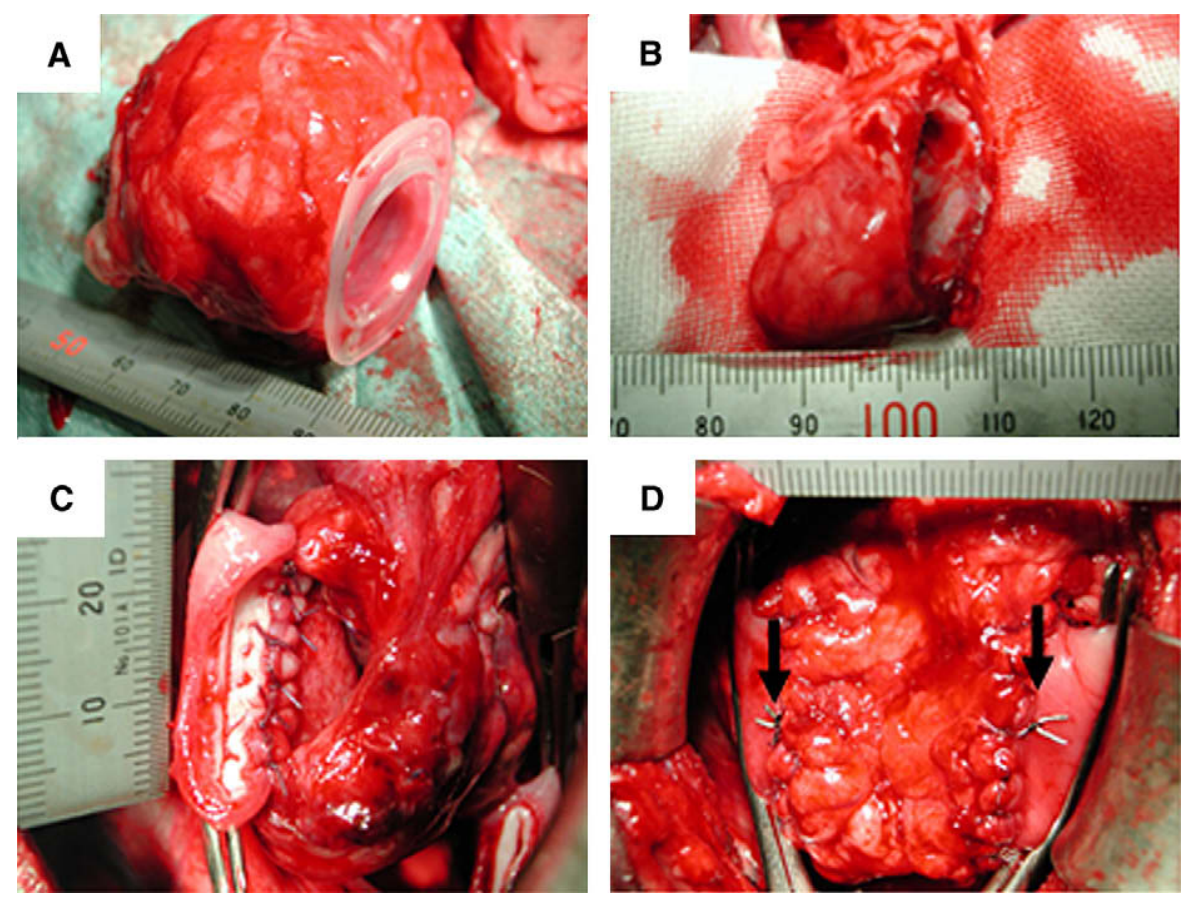

Figure 1. Surgical technique of esophageal replacement. $A$, The graft did not show any infection or adhesion to the abdominal cavity. B, The tube stent could be easily removed, and the scaffold developed into soft tubular tissue. C, The thoracic esophagus was mobilized, and a 3-cm length was resected and replaced by the graft. The anastomosis was completed with 3-0 Vicryl suture (Ethicon). D, Metal clips (arrows) were placed at the cut ends of the native esophagus as markers. 
stained with hematoxylin and eosin. The samples were stained immunohistochemically by use of an Envision + / HRP detection system (Dako, Kyoto, Japan). In brief, endogenous peroxidase activity was blocked with a peroxidase blocking reagent (Dako) for 5 minutes. Next, the sections or fixed cells were incubated with mouse monoclonal antibodies against $\alpha$-smooth muscle actin ( $\alpha$-SMA; Dako) and cytokeratin MNF116 (Dako) for 1 hour at room temperature. The sections were then incubated for 30 minutes at room temperature with peroxidase-labeled polymer conjugated to goat anti-rabbit or goat antimouse immunoglobulin. They were incubated with diaminobenzidine chromogen for 5 minutes, counterstained with hematoxylin, and mounted with a coverslip. Between each step, the sections were rinsed gently with Tris-buffered saline. Control sections were incubated without the primary antibodies.

\section{Results}

Autologous Oral Mucosal Epithelial Sheets

After 1 week in culture, the keratinocytes proliferated well and covered the amniotic membrane completely. The keratinocytes were then stained with Lugol solution (compound iodine glycerin) (data not shown). Fibroblasts penetrated the amniotic membrane, and the keratinocytes stratified into 4 to 5 layers (Figure 2).

\section{ITEE}

Three weeks after abdominal implantation, the graft maintained a tubular structure without any infection or adhesion. The stent was easily removed; there was no adhesion between the luminal epithelial layer and the stent. The graft was elevated into the right thoracic space through the right hemidiaphragm as a pedicle graft. Among the biopsy specimens of the ITEE of the $\mathrm{KF}(+)$ group, all but 2 cases showed a well-differentiated luminal surface with stratified keratinocytes and thick connective tissue similar to the smooth muscle tissue, although the amniotic membrane and PGA felt remained (Figure 3, $A$ to $E$ ). The biopsy specimens of B-2 and B-4 showed degeneration of keratinocytes and desquamation of the epithelial layer of ITEE.

\section{Postoperative Contrast Examination and Outcome}

In the $\mathrm{KF}(-)$ group, strictures were observed 1 week after the esophageal replacement. These strictures progressed to almost complete esophageal obstruction within 2 to 3 weeks (Table 1 and Figure 4, $A$ and $B$ ), although there were no infections or adhesions of the thoracic cavity (Figure 4, C). B-1, B-3, B5, and B-6 showed good passage immediately after esophageal replacement, and there were no problems with oral feeding (Table 1). At 8 to 11 weeks after esophageal replacement, 2 cases (B-2 and B-4) had strictures, probably because of epithelial layer desquamation. In the contrast study, the ITEE showed good distensibility. Esophageal peristalsis transferred
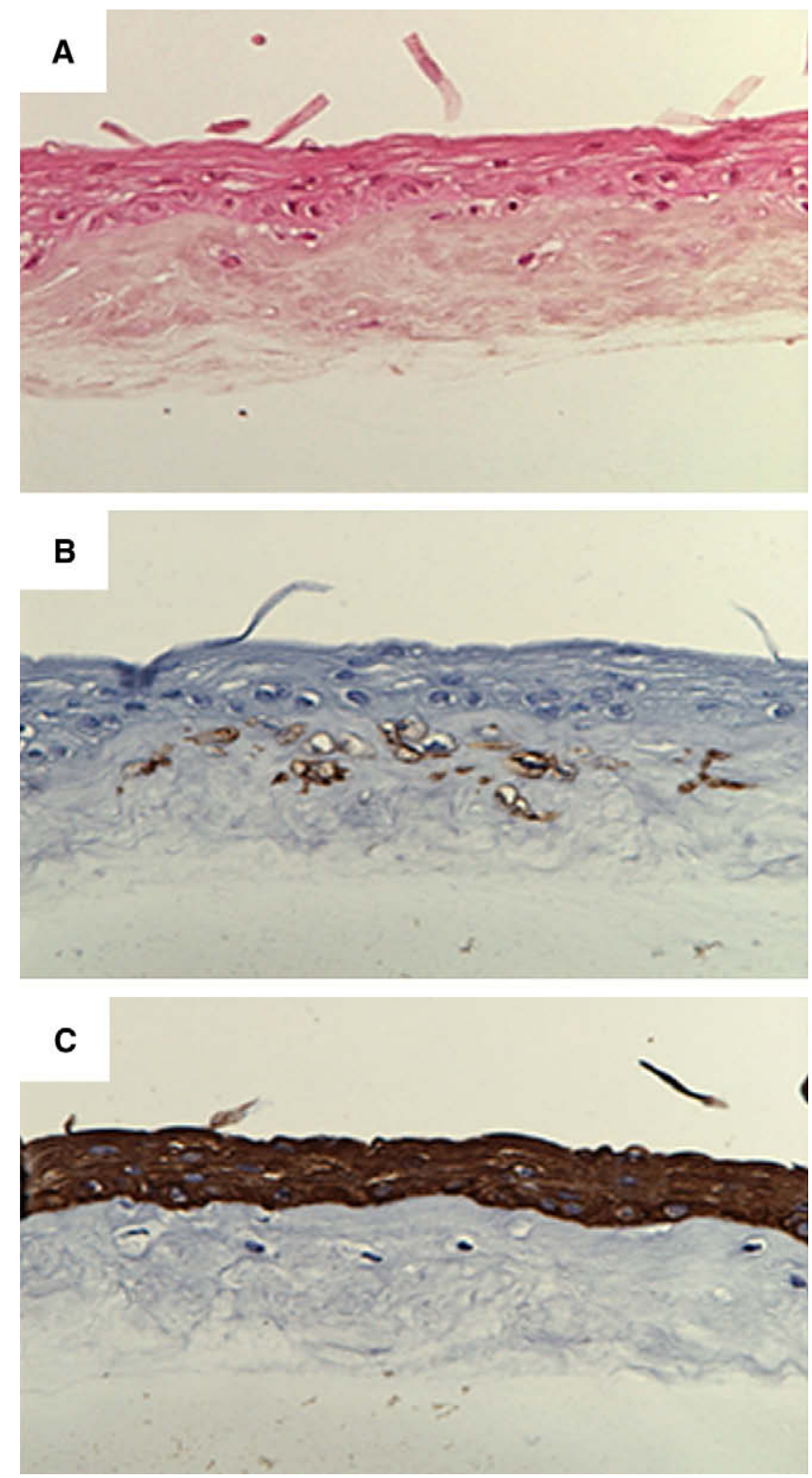

Figure 2. Histologic and immunohistochemical features of the oral epithelial cell sheets. A, Hematoxylin and eosin staining. B, Immunostaining for cytokeratin MNF116. C, Immunostaining for $\alpha$-smooth muscle actin ( $\alpha$-SMA) of autologous oral mucosal epithelial sheets. (Original magnification: $\times 200$.) Fibroblasts penetrated the amniotic membrane, and the keratinocytes were well differentiated and stratified into 4 to 5 layers.

food to the stomach, despite the absence of peristaltic activity in the ITEE itself (Figure 5, $A$ to $D$ ). As for the number of strictures, the $\mathrm{KF}(+)$ group had significantly fewer $(P=.014)$.

\section{Macroscopic and Microscopic Examinations}

In the $\mathrm{KF}(-)$ group, the graft surface was rough and showed cicatricial strictures (Figure 4,D). Inflammatory cells and 

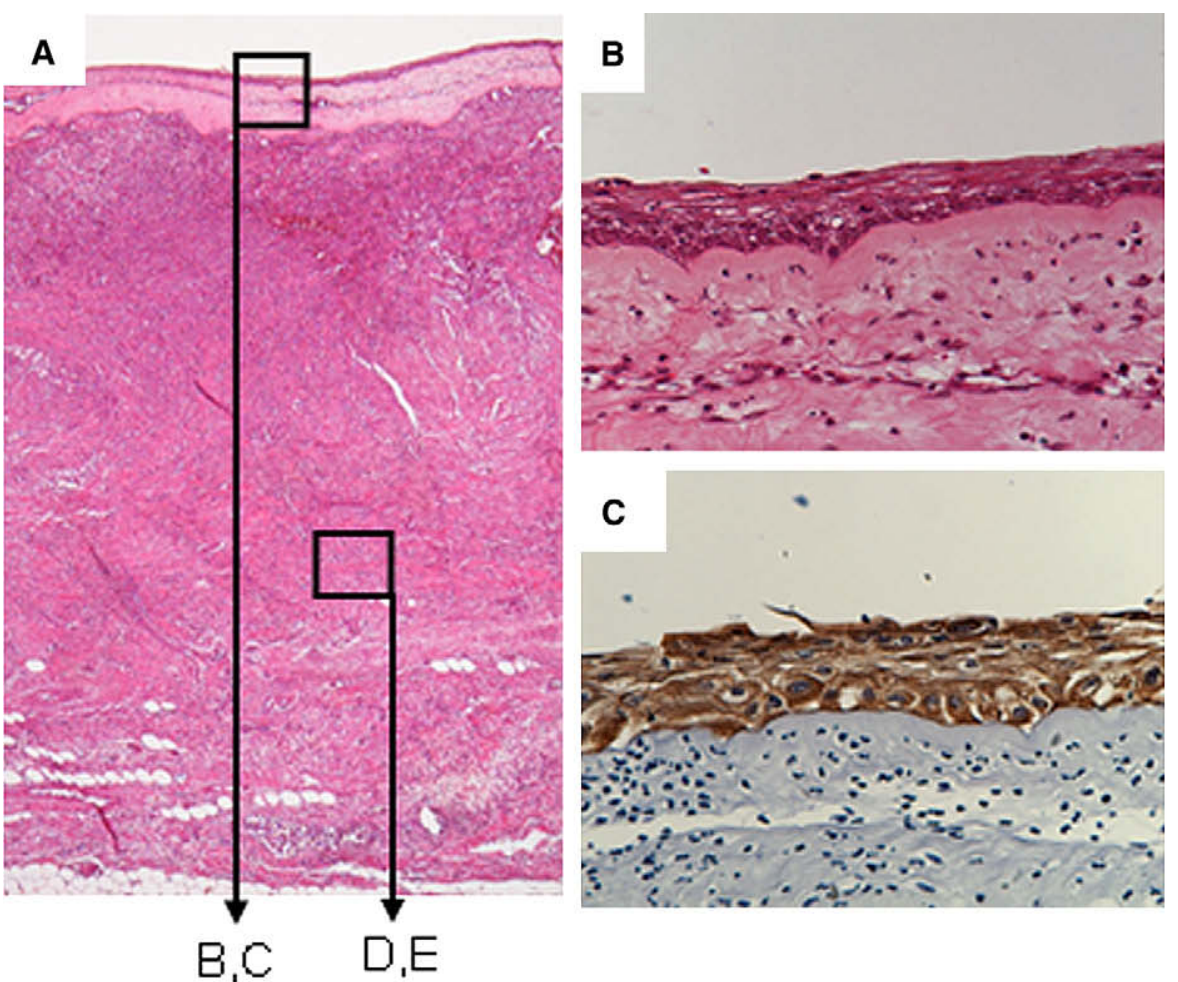

Figure 3. Histologic features of the grafts of the $K F(+)$ group (dog B-3), in situ tissue-engineered esophagus (ITEE). Hematoxylin and eosin staining is shown in A, B, and D. C, Immunostaining for cytokeratin MNF116. E, Immunostaining for $\alpha$-SMA. B to D, High-power views of the boxed regions in $A$. (Original magnifications: $A, \times 40$; $B$ and $C$, $\times 400$; $D$ and $E, \times 200$.) The surface of ITEE was covered by 4-5 layers of stratified, well-differentiated cells. The con-

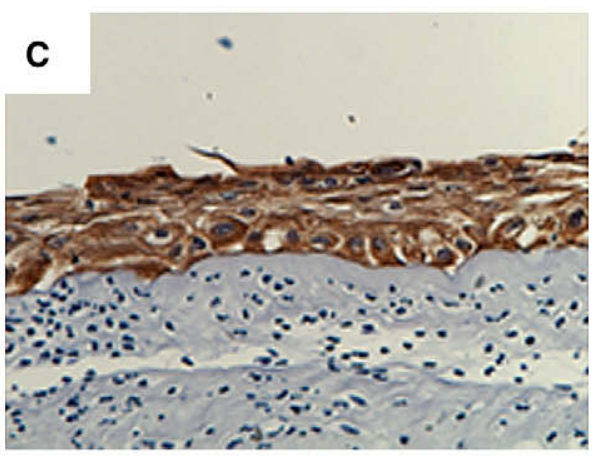
nective tissue of ITEE was similar to the smooth muscle tissue.
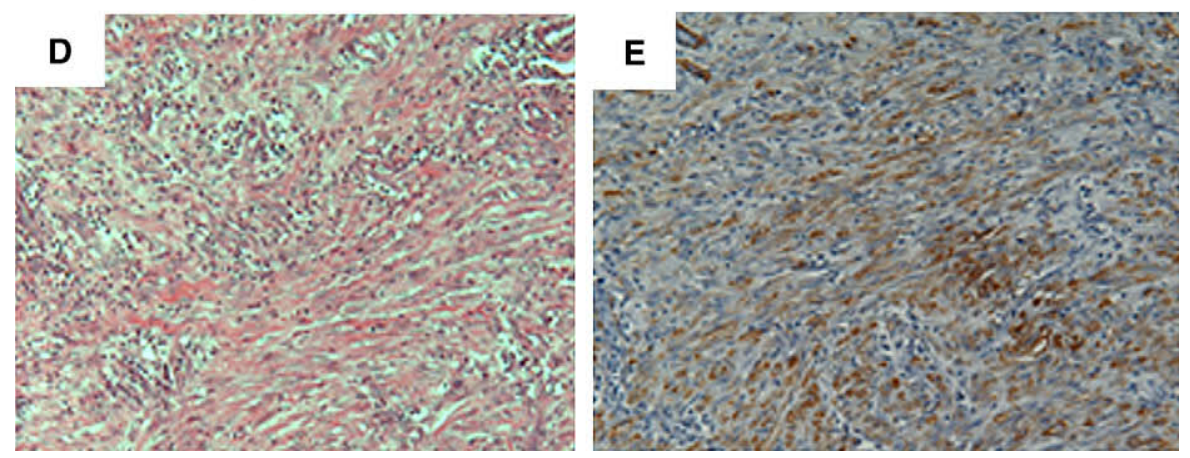

connective tissue infiltrated the graft. Epithelial cells did not completely cover the surface, although a few transitional epithelial cells lined the luminal graft surface at the anastomosis sites. In the $\mathrm{KF}(+)$ group, the ITEE surface was smooth, similar to the native esophageal surface. There were no strictures or esophagitis in the dogs B-1, B-3, B-5, and B-6 (Figure 5, $E$ and $F$ ), although dogs B-2 and B-4 showed stricture. Stratified keratinocytes covered the ITEE surface. While the ITEE surface contained smooth muscle-like tissue, no glandular structure was observed (Figure 6). The ITEE surfaces of B-1, B-3, B-5, and B-6 showed thicker smooth muscle-like tissue and a well-differentiated epithelial layer (12-15 layers) than the ITEE surfaces in B-2 and B-4 (2 to 3 layers). The smooth muscle cells of the ITEE showed polarity with time in B-1, B-3, B-5, and B-6. The thickness of the squamous epithelium, muscularis mucosa, and smooth muscle tissue of the ITEE was similar to the thickness of the adjacent native esophagus.

\section{Discussion}

Recent advances in the field of tissue engineering allow regeneration of many tissues and organs for clinical use. ${ }^{11,12}$ In the field of esophageal regeneration, some experiments with animal models have been reported in the past. ${ }^{13}$ Grikscheit's group ${ }^{14}$ reported the use of tissue-engineered esophagus, which they developed using intestinal organoids harvested from neonatal rats. Application of their procedure to humans, however, has multiple problems, such as ethical issues, the requirement of long-term immunosuppression, and the availability of large amounts of neonatal tissue. ${ }^{15,16}$ Badylak and colleagues ${ }^{17,18}$ used an extracellular matrix scaffold for esophageal regeneration in the canine model. 
TABLE 1. Summary of outcome and survival time

\begin{tabular}{cccl}
\hline Group & Dog No. & Survival time (d) & \multicolumn{1}{c}{ Outcome } \\
\hline $\mathrm{KF}(-)$ & $\mathrm{A}-1$ & 19 & Stricture \\
& $\mathrm{A}-2$ & 22 & Stricture \\
& $\mathrm{A}-3$ & 18 & Stricture \\
& $\mathrm{A}-4$ & 17 & Stricture \\
& $\mathrm{A}-5$ & 24 & Stricture \\
$\mathrm{KF}(+)$ & $\mathrm{A}-6$ & 19 & Stricture \\
& $\mathrm{B}-1$ & 70 & Planned death \\
& $\mathrm{B}-2$ & 28 & Stricture \\
& $\mathrm{B}-3$ & 140 & Planned death \\
& $\mathrm{B}-4$ & 56 & Stricture \\
& $\mathrm{B}-5$ & 350 & Planned death \\
& $\mathrm{B}-6$ & 420 & Planned death \\
\hline
\end{tabular}

Additional research groups used porcine small intestinal submucosa ${ }^{19-23}$ in rat models. Badylak and associates ${ }^{17}$ reported that extracellular matrix with adjacent muscle tissue showed no stricture and clinically acceptable results for treatment of esophageal ulcerations after endoscopic submucosal dissection. Small intestinal submucosa and extracellular matrix were also xenobiotic material and have a potential for unknown viral infection. The ITEE materials used in this study, specifically, PGA felt, have already been used clinically, ${ }^{8-10}$ and human amniotic membrane has already been used clinically for tissue-engineered cornea or $\operatorname{skin}^{5-7,24}$; furthermore we used autologous oral mucosal cells and sera. Thus, the use of ITEE avoids transplantation problems such as rejection, infection, long-term immunosuppression, donor scarcity, and related ethical issues.

Yamamoto, ${ }^{25}$ Takimoto, ${ }^{26}$ Hori, ${ }^{27}$ and their associates pursued organ tissue engineering with autologous cells and used collagen scaffolds, either alone or seeded with autologous mesenchymal stem cells, for cervical or intrathoracic esophageal regeneration in canine models. However, their procedure required prolonged retention of a silicone tube, and the regenerated intrathoracic esophagi developed strictures owing to the lack a muscle layer, which is essential for maintenance of the luminal caliber. This study showed that no strictures developed in the ITEE immediately after esophageal replacement. Food passage was good, and there were no complications of feeding a normal diet for 420 days. The thickness of the squamous epithelium, muscularis mucosa, and smooth muscle tissue of the ITEE was similar to the thickness of the adjacent native intrathoracic esophagus. Furthermore, ITEE exhibits good distensibility and physical strength; however, it does not have esophageal glands or peristaltic activity. Esophageal reconstruction does not necessarily require peristalsis or esophageal mucus in the graft. In fabricating an artificial esophagus, we believe ITEE has the necessary functions.

Within a few weeks of the esophageal replacement, the grafts in the $\mathrm{KF}(-)$ group showed strictures. Inflammatory cells and connective tissue infiltrated the grafts, which also showed scar formation. We did not observe smooth muscle tissue. We believe this resulted from chronic infection on
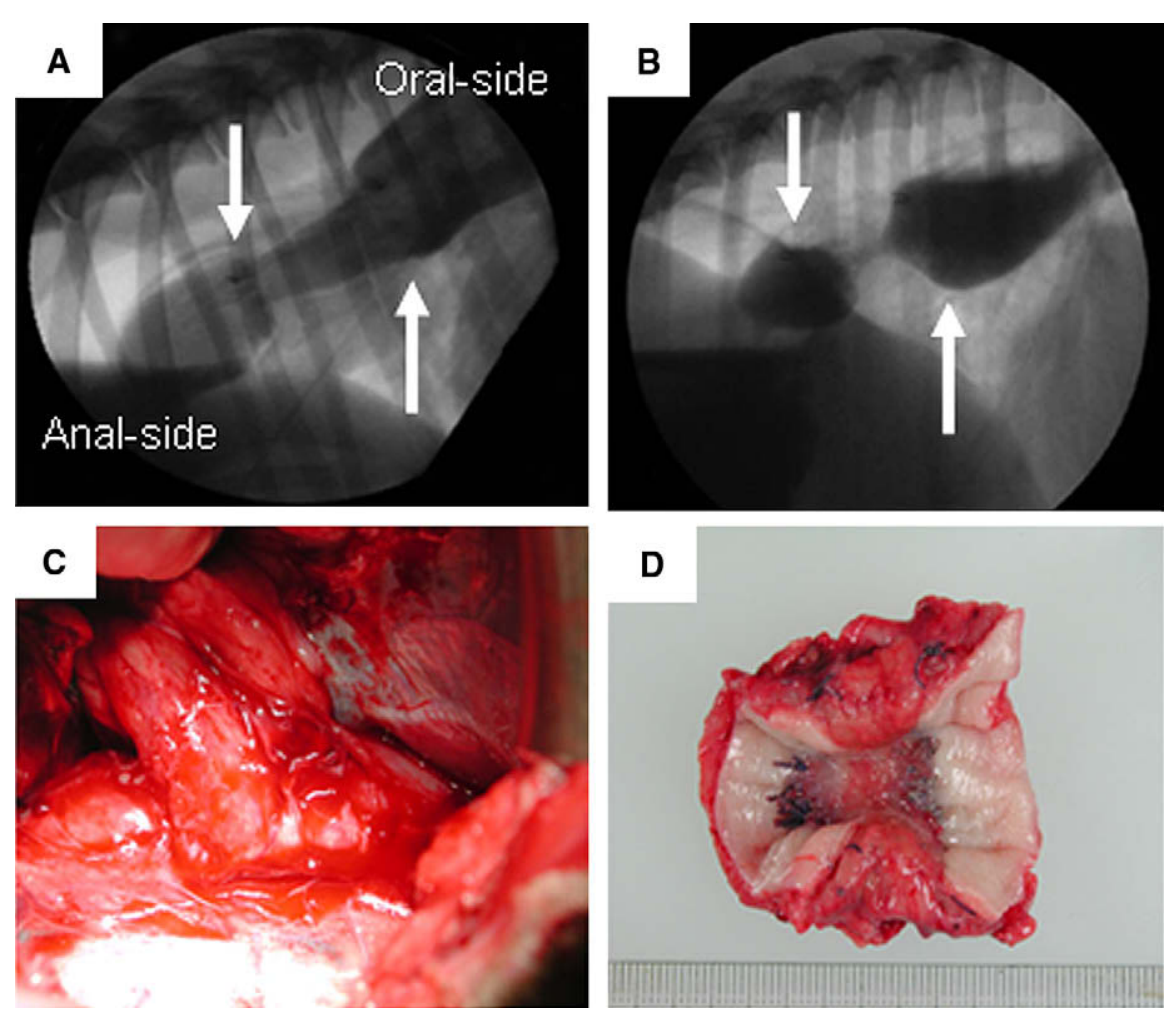

Figure 4. Postoperative contrast study: macroscopic findings and histologic features of the $\mathrm{KF}(-)$ group (dog A-2). A and $B$, This esophagogram is the side view of the intrathoracic esophagus. The right upper corner indicates the oral side and the left lower corner indicates the anal side. The arrows indicate metal clips at the cut ends of the native esophagus. $A$, At 1 week after esophageal replacement, the graft showed a stricture. B, At 22 days after esophageal replacement, the graft showed almost complete obstruction. C, No infection or adhesion of the thoracic cavity noted. D, The surface of the ITEE was rough and showed a cicatricial stricture. 

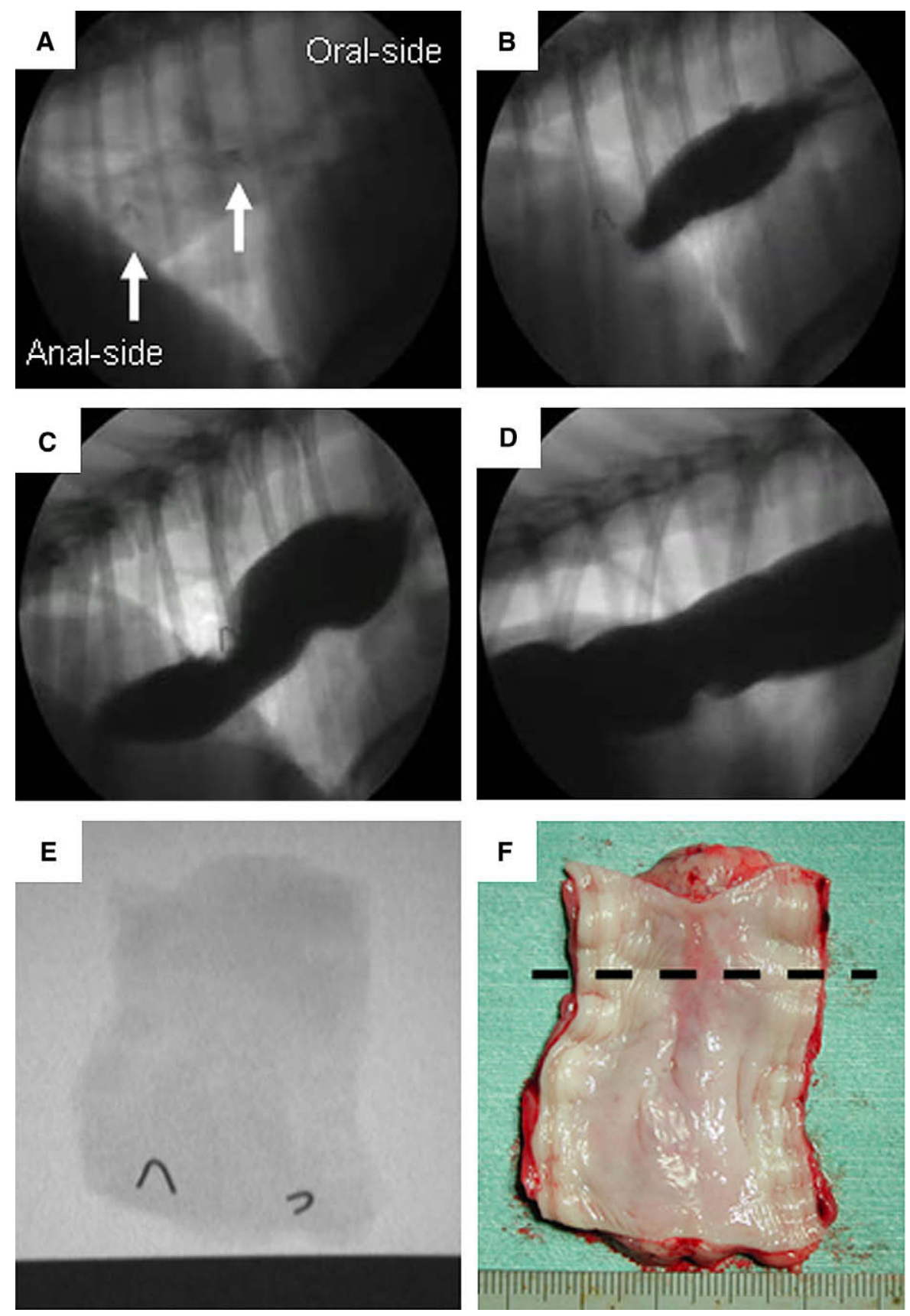

Figure 5. Postoperative contrast study: macroscopic findings of the $K F(+)$ group (dog B-5) at 350 days after esophageal replacement. $A$, Metal clips (arrows) at the cut ends of the native esophagus were detected, and placement of the ITEE was confirmed by radiography. B to D, Sequential photographs of the contrast study. ITEE showed good distensibility, and esophageal peristalsis smoothly transferred food into the stomach. E, X-ray image of F. Metal clips at the cut ends of the native esophagus were detected by radiography. $F$, The ITEE shows a smooth surface similar to the native esophagus. The surface showed no signs of stricture or esophagitis. Histologic and immunohistochemical features of the ITEE at the broken line in $\mathrm{F}$ are shown in Figure 6. the graft subsequent to bacterial exposure. In contrast, in the $\mathrm{KF}(+)$ group, epithelial cell sheets may protect the underlying smooth muscle tissue layer from bacterial exposure. Badylak and associates ${ }^{17}$ reported that strictures formed during esophageal reconstruction using an extracellular matrix scaffold without adjacent muscle tissue. In our study, grafts without smooth muscle tissue developed strictures within a few weeks (data not shown). These results suggest that, similar to the epithelium, muscle tissue is necessary to prevent the development of graft strictures.
Two culture systems have been reported for oral epithelial cell sheets. The first used temperature-responsive culture inserts $^{4,28}$ and the second used human amniotic membrane. ${ }^{5-7}$ We used human amniotic membrane to create an oral mucosal epithelial cell sheet because it has favorable biological properties such as poor immunogenicity, anti-inflammatory properties, and surgical operability. ${ }^{5-7}$ Currently, the preferred method for cultivating oral epithelial cells requires the use of xenobiotic materials such as fetal bovine serum and 3 T3 feeder cells. Inatomi, ${ }^{5}$ Nakamura, ${ }^{6,7}$ and their 


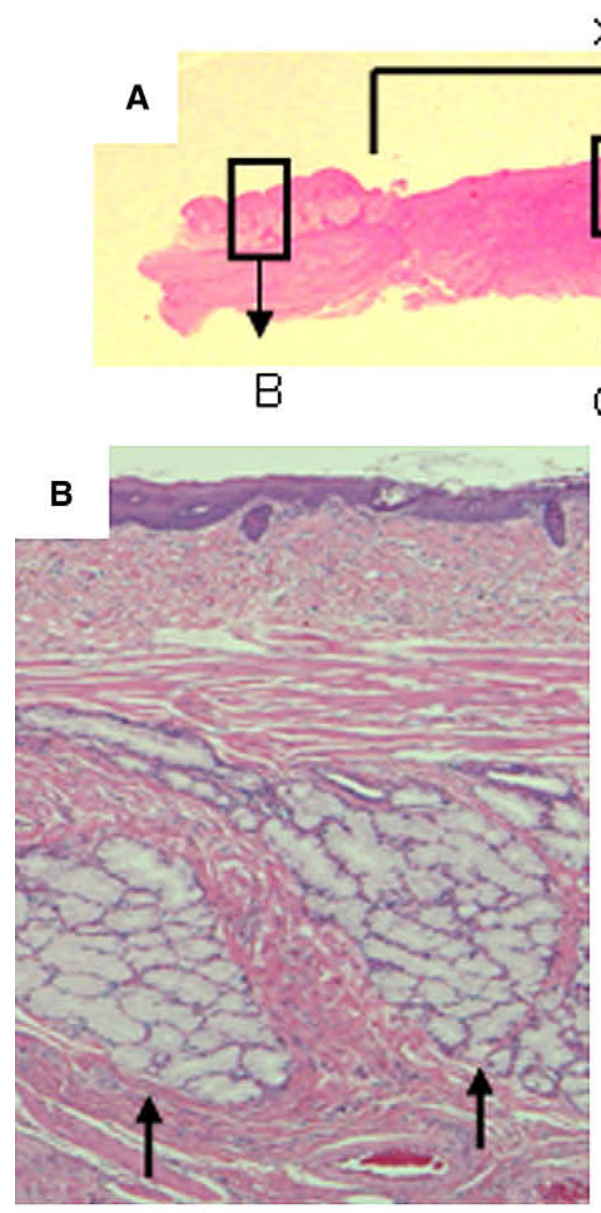

*
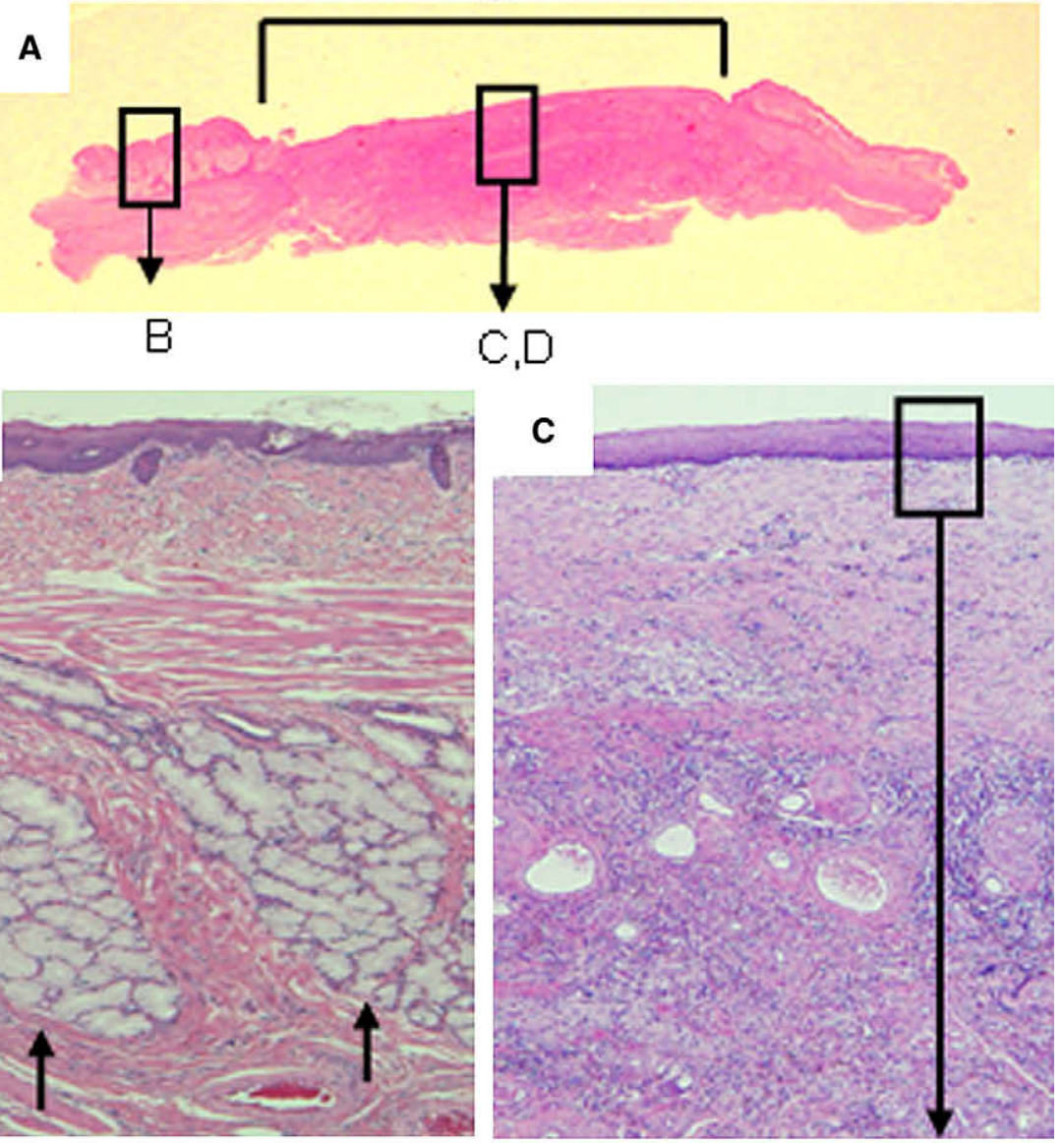

E

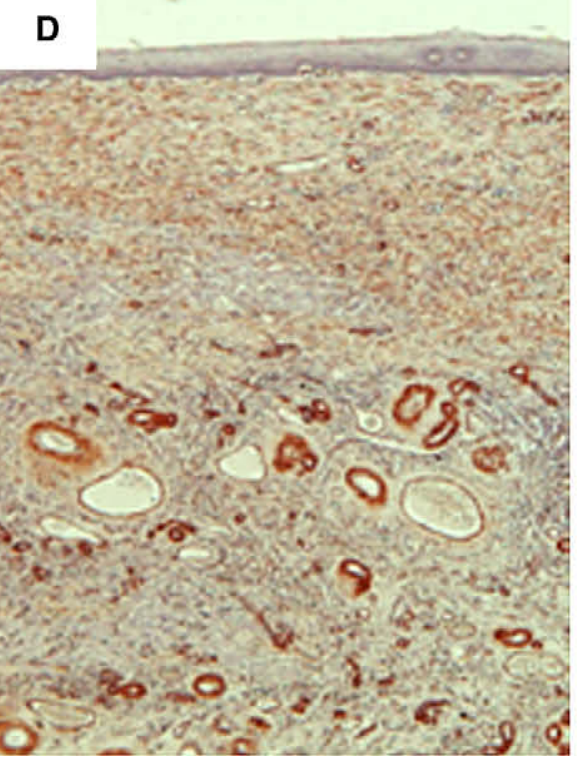

Figure 6. Histologic and immunohistochemical features of the $K F(+)$ group (dog B-5). A, Hematoxylin and eosin staining at the broken line in Figure 5 , $F$ *ITEE; original magnification, $\times 4$. B to $D$, High-power views of the boxed region in $\mathbf{A}$; original magnification, $\times \mathbf{1 0 0}$. $E$, High-power view of the boxed region in C; original magnification, $\times \mathbf{4 0 0}$. Hematoxylin and eosin staining is shown in $A, B, C$, and $E$. D, Immunostaining for $\alpha$-SMA (B) showed the histologic features of the native esophagus. The arrow indicates the glandular structure. The ITEE surface was covered by welldifferentiated, stratified (12-15 layers) keratinocytes and showed thick smooth muscle-like tissue that was similar to that of the native muscle layer, but no glandular structures. associates used autologous serum instead of fetal bovine serum, but they did use 3 T3 feeder cells. We modified their methods and used both autologous blood serum and autologous oral fibroblasts instead of 3 T3 feeder cells. Our method was simple and similar to previous reports: the cultivated oral epithelium demonstrated 4 to 5 layers of stratified, well-differentiated cells. ${ }^{5-7}$ The amniotic membrane degraded 6 to 8 weeks after implantation, and the implanted cell remained 
and proliferated (data not shown). These results were similar to those of previous reports. ${ }^{5-7}$ Furthermore, oral wound healing was faster and had less scar formation when compared with normal skin healing because of growth factors produced by oral fibroblasts. ${ }^{29,30}$ Using oral fibroblasts may promote the development of the epithelial layer and prevent scar formation in ITEE, although we believe a key factor for preventing shrinkage of the graft is keratinocytes.

Within 3 weeks of abdominal implantation, the scaffold received blood supply from the omentum and formed the ITEE. When the period of abdominal implantation was less than 3 weeks, the oral epithelial layer was only weakly adherent and smooth muscle tissue did not form (data not shown). In abdominal implantation periods greater than 3 weeks, the epithelial layer tended to degenerate and desquamate (data not shown). Therefore, we fixed the abdominal implantation period at 3 weeks. Nevertheless, this was not sufficient since strictures developed in 2 cases of the $\mathrm{KF}(+)$ group. These cases show epithelial degeneration and desquamation of the graft before replacement. We believe the epithelial layer was important in preventing shrinkage of the graft. For epithelial cell differentiation, air exposure reduces intercellular spaces in superficial cells and promotes the development of barrier function. ${ }^{31,32}$ To improve the abdominal implantation procedure, it might be effective to expose the scaffold surface to the air. In the future, we plan to use a mesh tube stent instead of the polypropylene tube stent, and we will take outside air into this stent by tubostomy.

In this study, we developed a full-circumference and full-thickness artificial intrathoracic esophagus, although these ITEEs are too short to evaluate clinical utility. These results, however, suggest that ITEE has potential for esophageal reconstruction without using other digestive tract tissues and will be useful for patients who are lacking another suitable substitute. In the future, we plan to fabricate longer segments of ITEE by this procedure and evaluate the function compared with stomach or intestine in an animal model.

\section{Conclusion}

Our results show that ITEE can replace the intrathoracic esophagus in a canine model. This procedure offers a promising surgical approach to esophageal diseases. In the future, we plan to fabricate longer segments of ITEE by this procedure and evaluate the function compared with stomach or intestine in an animal model and investigate the long-term safety of this procedure.

\section{References}

1. Linden PA, Sugarbaker DJ. Surgical procedures to resect and replace the esophagus. In: Michael JZ, Stanley WA, eds. Maingot's abdominal operations. 11th ed. New York: McGraw-Hill; 2007. p. $305-32$.
2. Nakase Y, Nakamura T, Kin S, Nakashima S, Yoshikawa T, Kuriu Y, et al. Endocrine cell and nerve regeneration in autologous in situ tissue-engineered small intestine. J Surg Res. 2007;137:61-8.

3. Nakase $Y$, Hagiwara A, Nakamura $T$, Kin $S$, Nakashima $S$, Yoshikawa T, et al. Tissue engineering of small intestinal tissue using collagen sponge scaffolds seeded with smooth muscle cells. Tissue Eng. 2006; 12:403-12

4. Ohki T, Yamato M, Murakami D, Takagi R, Yang J, Namiki H, et al. Treatment of oesophageal ulcerations using endoscopic transplantation of tissue-engineered autologous oral mucosal epithelial cell sheets in a canine model. Gut. 2006;55:1704-10.

5. Inatomi T, Nakamura T, Kojyo M, Koizumi N, Sotozono C, Kinoshita S. Ocular surface reconstruction with combination of cultivated autologous oral mucosal epithelial transplantation and penetrating keratoplasty. $\mathrm{Am}$ J Ophthalmol. 2006;142:757-64.

6. Nakamura T, Inatomi T, Sotozono C, Ang LP, Koizumi N, Yokoi N, et al. Transplantation of autologous serum-derived cultivated corneal epithelial equivalents for the treatment of severe ocular surface disease. Ophthalmology. 2006;113:1765-72.

7. Nakamura T, Ang LP, Rigby H, Sekiyama E, Inatomi T, Sotozono C, et al. The use of autologous serum in the development of corneal and oral epithelial equivalents in patients with Stevens-Johnson syndrome. Invest Ophthalmol Vis Sci. 2006;47:909-16.

8. Hayashibe A, Sakamoto K, Shinbo M, Makimoto S, Nakamoto T. New method for prevention of bile leakage after hepatic resection. J Surg Oncol. 2006;94:57-60.

9. Miyamoto H, Futagawa T, Wang Z, Yamazaki A, Morio A, Sonobe S, et al. Fibrin glue and bioabsorbable felt patch for intraoperative intractable air leaks. Jpn J Thorac Cardiovasc Surg. 2003;51:232-6.

10. Kawamura M, Kase K, Sawafuji M, Watanabe M, Horinouchi H, Kobayashi K. Staple-line reinforcement with a new type of polyglycolic acid felt. Surg Laparosc Endosc Percutan Tech. 2001;11:43-6.

11. Langer R, Vacanti J. Tissue engineering. Science. 1993;260:920-6.

12. Ikada Y. Animal and human trials of engineered tissues. In: Ikada Y, ed. Tissue engineering: fundamentals and applications. London: Elsevier; 2006. p. 91-221.

13. Ikada Y. Gastrointestinal system. In: Ikada Y, ed. Tissue engineering: fundamentals and applications. London: Elsevier; 2006. p. 205-10.

14. Grikscheit T, Ochoa ER, Srinivasan A, Gaissert H, Vacanti JP. Tissueengineered esophagus: experimental substitution by onlay patch or interposition. J Thorac Cardiovasc Surg. 2003;126:537-44.

15. Grikscheit T, Siddique A, Ochoa ER, Srinivasan A, Alsberg E, Hodin RA, et al. Tissue-engineered small intestine improves recovery after massive small bowel resection. Ann Surg. 2004;240:748-54.

16. Warner BW. Tissue engineered small intestine: a viable clinical option? Ann Surg. 2004;240:755-6.

17. Badylak SF, Vorp DA, Spievack AR, Simmons-Byrd A, Hanke J, Freytes DO, et al. Esophageal reconstruction with ECM and muscle tissue in a dog model. J Surg Res. 2005;128:87-97.

18. Badylak S, Meurling S, Chen M, Spievack A, Simmons-Byrd A. Resorbable bioscaffold for esophageal repair in a dog model. J Pediatr Surg. 2000;35:1097-103.

19. Yamataka A, Wang K, Kobayashi H, Segawa O, Miyahara K, Sueyoshi N, et al. Transplantation of newborn esophagus: an experimental study. J Pediatr Surg. 2001;36:1255-7.

20. Yamataka A, Wang K, Kobayashi H, Unemoto K, Miyahara K, Sueyoshi N, et al. Transplantation of newborn esophagus: an experimental study. J Pediatr Surg. 2001;36:1255-7.

21. Urita Y, Komuro H, Chen G, Shinya M, Kaneko S, Kaneko M, et al. Regeneration of the esophagus using gastric acellular matrix: an experimental study in a rat model. Pediatr Surg Int. 2007;23:21-6.

22. Lopes MF, Cabrita A, Ilharco J, Pessa P, Paiva-Carvalho J, Pires A, et al. Esophageal replacement in rat using porcine intestinal submucosa as a patch or a tube-shaped graft. Dis Esophagus. 2006;19:254-9.

23. Lopes MF, Cabrita A, Ilharco J, Pessa P, Patricio J. Grafts of porcine intestinal submucosa for repair of cervical and abdominal esophageal defects in the rat. J Invest Surg. 2006;19:105-11.

24. Yang L, Shirakata Y, Shudou M, Dai X, Tokumaru S, Hirakawa S, et al New skin-equivalent model from de-epithelialized amnion membrane. Cell Tissue Res. 2006;326:69-77. 
25. Yamamoto Y, Nakamura T, Shimizu Y, Matsumoto K, Takimoto Y, Kiyotani $\mathrm{T}$, et al. Intrathoracic esophageal replacement in the dog with the use of an artificial esophagus composed of a collagen sponge with a double-layered silicone tube. J Thorac Cardiovasc Surg. 1999;118: 276-86.

26. Takimoto Y, Nakamura T, Yamamoto Y, Kiyotani T, Teramachi M, Shimizu Y. The experimental replacement of a cervical esophageal segment with an artificial prosthesis with the use of collagen matrix and a silicone stent. J Thorac Cardiovasc Surg. 1998;116:98-106.

27. Hori Y, Nakamura T, Kimura D, Kaino K, Kurokawa Y, Satomi S, et al. Effect of basic fibroblast growth factor on vascularization in esophagus tissue engineering. Int J Artif Organs. 2003;26:241-4.

28. Hayashida Y, Nishida K, Yamato M, Yang J, Sugiyama H, Watanabe K, et al. Ocular surface reconstruction using autologous rabbit oral mucosal epithelial sheets fabricated ex vivo on a temperature-responsive culture surface. Invest Ophthalmol Vis Sci. 2005;46:1632-9.
29. Szpaderska AM, Walsh CG, Steinberg MJ, DiPietro LA. Distinct patterns of angiogenesis in oral and skin wounds. J Dent Res. 2005;84: $309-14$.

30. Okazaki M, Yoshimura K, Uchida G, Harii K. Elevated expression of hepatocyte and keratinocyte growth factor in cultured buccal-mucosaderived fibroblasts compared with normal-skin-derived fibroblasts. J Dermatol Sci. 2002;30:108-15.

31. Kawakita T, Espana EM, He H, Smiddy R, Parel JM, Liu CY, et al. Intrastromal invasion by limbal epithelial cells is mediated by epithelial-mesenchymal transition activated by air exposure. Am J Pathol. 2005;167: 381-93.

32. Ban Y, Cooper LJ, Fullwood NJ, Nakamura T, Tsuzuki M, Koizumi N, et al. Comparison of ultrastructure, tight junction-related protein expression and barrier function of human corneal epithelial cells cultivated on amniotic membrane with and without air-lifting. Exp Eye Res. 2003;76: $735-43$. 